\title{
Erratum to: Criteria for the evaluation of life cycle assessment software packages and life cycle inventory data with application to concrete
}

\author{
Mary Ann Curran ${ }^{1}$ \\ (C) Springer-Verlag Berlin Heidelberg 2017 \\ Erratum to: Int J Life Cycle Assess \\ DOI 10.1007/s11367-016-1060-6 \\ Erratum to: Int J Life Cycle Assess \\ DOI 10.1007/s11367-016-1141-6
}

Owing to an unfortunate misunderstanding, a letter referring to an original article was published ahead of that article.

The letter (Mark Goedkoop: In response to "Criteria for the evaluation of life cycle assessment software packages and life cycle inventory data with application to concrete" by Seto et al. (2016), DOI 10.1007/s11367-016-1141-6) appeared on pages 1213-1214 of Volume 21, Number 8.

The article to which it refers (Karina E. Seto, Daman K. Panesar, Cameron J. Churchill: Criteria for the evaluation of life cycle assessment software packages and life cycle inventory data with application to concrete, DOI 10.1007/s11367016-1060-6) was published online on 1 March 2016 and is included in the current issue.

We apologize sincerely for this mistake and for any inconvenience caused.

Mary Ann Curran is the Editor-in-Chief of this journal.

The online version of the original article can be found at doi:10.1007/ s11367-016-1060-6.

The online version of the response letter can be found at doi:10.1007/ s11367-016-1141-6.

Mary Ann Curran

macurran5137@gmail.com

1 Rock Hill, SC, USA 